\title{
Plaque psoriasis in children and adolescents - the role of etanercept
}

\author{
This article was published in the following Dove Press journal: \\ Psoriasis: Targets and Therapy \\ 9 June 2012 \\ Number of times this article has been viewed
}

\section{Federica Ricceri \\ Lara Tripo \\ Leonardo Pescitelli \\ Francesca Prignano \\ Division of Clinical, Preventive and Oncology Dermatology, Department of Critical Care Medicine and Surgery, University of Florence, Florence, Italy}

Background: Childhood-onset psoriasis affects approximately one-third of the psoriatic population. Among many potential treatments of childhood psoriasis, biological agents are emerging as a valuable option in the management of this disease. In Europe, etanercept has recently been approved for children aged 6 years and over. Data from a well-designed clinical trial indicate that in children, etanercept effectively reduces psoriasis symptoms, with beneficial effects evident as early as 4 weeks after the onset of therapy. The treatment is generally well tolerated; mild injection site reactions are the most common adverse events reported in the literature. Published data of etanercept use in children show promising results, but further clinical studies are necessary to confirm its long-term efficacy and safety.

Keywords: pediatric psoriasis, anti-TNF- $\alpha$, etanercept

\section{Introduction}

Psoriasis is a chronic immune-mediated inflammatory skin disease characterized by erythematosquamous lesions; the lesions can be extremely variable in distribution on body surface, severity, and extension. ${ }^{1}$ Like all forms of autoimmunity, susceptibility is genetic, but environmental triggers are required to start disease activity.

The prevalence of psoriasis ranges between $1 \%-3 \%$ in the population worldwide. ${ }^{2}$ It may begin at any age. In more than $33 \%$ of patients, the initial presentation of psoriasis occurs within the first two decades of life. ${ }^{3}$ It is estimated that $10 \%$ of patients develop psoriasis before the age of 10 years, and $2 \%$ before the age of 2 years. ${ }^{4}$

Psoriasis in children and adolescents may represent "early-onset disease," which is associated with specific human leukocyte antigen (HLA) subtypes including HLA Cw6 and B57. ${ }^{5}$ Early onset psoriasis is often an indicator of a more severe disease phenotype. The psychosocial impairment, in addition to the physical affliction that can result from psoriasis, is a reminder that early recognition and management of psoriasis in children and adolescents is crucial.

Pediatric psoriasis consists of three age groups of psoriatic patients: infantile psoriasis (a self-limited disease of infancy), psoriasis with early onset, and pediatric psoriasis with psoriatic arthritis. The varied clinical presentations in childhood include plaque-type, guttate, erythrodermic, napkin, and nail-based disease. Plaque type is the most common form of disease in children; erythroderma, arthropathy, and localized and generalized pustular psoriasis are less frequently observed. Psoriasis in children is more frequently precipitated by infections and manifests as acute guttate psoriasis. ${ }^{6}$

Many studies have investigated the use of standard psoriasis therapies in children with psoriasis, including topical treatments, phototherapy, and systemic therapies. 
When treating children with psoriasis, it is important to educate both patients and parents about the nature of the disease. Psoriasis is a chronic skin disorder without a permanent therapy and therefore the goal of treatment is to establish disease control and extend the periods between flares. The patient's age, quality of life factors, Psoriasis Area and Severity Index (PASI) score, and therapeutic preferences should all be considered when choosing treatment.

Topical therapy remains the first-line treatment of skinlimited disease in children. Corticosteroids remain the firstline topical agents. However, very high potency steroids should be avoided in children if possible or used sparingly in combination with a regime of steroid-sparing alternatives such as coal tar, vitamin D analogues, or retinoids.

In cases of refractory, diffuse, or severe forms of psoriasis, systemic treatments are indicated. Phototherapy and systemic therapies (such as retinoids, cyclosporine, and methotrexate) have limited use because of low tolerability in children, cumulative adverse effects, and teratogenicity. ${ }^{7-9}$

Newer, more targeted biologic treatments, specifically tumor necrosis factor (TNF)- $\alpha$ inhibitors, are also gaining popularity in the management of refractory psoriasis. TNF is a cytokine that plays a central pro-inflammatory role in many chronic inflammatory diseases. The TNF- $\alpha$ inhibitors represent an important new group of agents which significantly improve symptoms and signs, function, and quality of life, and induce remission in patients with chronic inflammatory and rheumatic conditions. In patients with psoriasis, the immune system releases a cytokine response that enhances the inflammatory response and leads to the epidermal hyperproliferation and perpetuation of the disease. Biologic agents such as TNF- $\alpha$ antagonists stop the inflammatory pathways active in psoriasis.

Anti-TNF- $\alpha$ have been used for more than a decade for pediatric autoimmune diseases including rheumatoid arthritis, ${ }^{10}$ juvenile idiopathic arthritis, ${ }^{11}$ and Crohn's disease. ${ }^{12}$ Juvenile rheumatoid arthritis patients have the longest usage history with TNF inhibitors, with up to 8 years of published safety and efficacy data.

\section{Etanercept}

Etanercept is a human soluble TNF- $\alpha$ type 2 receptor fused to the constant portion of human immunoglobulin-G1; it antagonizes the effects of endogenous TNF.

Etanercept is widely used ${ }^{13}$ to treat adult patients who have moderate-to-severe plaque psoriasis. Numerous clinical trials of etanercept have shown significantly reduced disease severity, fatigue, and symptoms of depression, and significantly improved overall health-related quality of life in adult patients with psoriasis. It is also indicated for patients as young as 2 years or older for treatment of moderately to severely active polyarticular juvenile idiopathic arthritis. ${ }^{14}$

In January 2009, etanercept was approved in Europe for the treatment of chronic, severe plaque psoriasis in children aged 8 years and older. Recently, the therapeutic application was extended to a lower age range. The actual indication is for treatment of chronic severe plaque psoriasis in children and adolescents from the age of 6 years old who are inadequately controlled by, or are intolerant to, other systemic therapies or phototherapies.

The approved dosage forms of etanercept include powder and solvent to produce a solution for injection, and solution for injection in a prefilled syringe. All etanercept dosage forms are intended for subcutaneous injection. The approved dose for the treatment of chronic, severe, plaque psoriasis in children and adolescents from the age of 6 years old is $0.8 \mathrm{mg} / \mathrm{kg}$ (up to a maximum of $50 \mathrm{mg}$ per dose) once weekly for up to 24 weeks. Treatment should be discontinued in patients who show no response after 12 weeks. If re-treatment is indicated, the above guidance on treatment duration should be followed. There is generally no applicable use of etanercept in children under the age of 6 years old in the indication for plaque psoriasis. Treatment should not be initiated in patients with active infections, including chronic or localized infections.

The evidence published in the last 5 years on the use of etanercept in pediatric psoriasis includes case reports, case series, and a randomized, double-blind, placebo controlled trial (Table 1). The youngest patient treated with etanercept reported in the medical literature is a 22-month-old child affected by suberythrodermic recalcitrant psoriasis. ${ }^{15}$

As the indication for pediatric plaque psoriasis is restricted to severe disease where other systemic therapies are unsuitable because of contra-indications or intolerance or have not been effective, etanercept remains a third-line option for children with plaque psoriasis.

\section{Efficacy}

In the literature there are several case reports attesting to etanercept efficacy in the treatment of various forms of pediatric psoriasis. ${ }^{16-20}$

However, only a few studies have been conducted in pediatric populations, compared to the large amount of data regarding etanercept efficacy in adult psoriasis.

A pioneering retrospective study of etanercept treatment was made in 9 children and adolescents (aged 8-17 years) with recalcitrant generalized psoriasis who were dosed 
Table I Summary table

\begin{tabular}{|c|c|c|c|c|}
\hline Study & $\begin{array}{l}\text { Number } \\
\text { of patients }\end{array}$ & Intervention & Conclusion & $\begin{array}{l}\text { Level of } \\
\text { evidence }\end{array}$ \\
\hline Fabrizi et al ${ }^{15}$ & 1 & $\begin{array}{l}\text { Etanercept } \\
(0.4 \mathrm{mg} / \mathrm{kg} \text { twice weekly) for } 6 \text { months }\end{array}$ & $\begin{array}{l}\text { "Suberythrodermic, recalcitrant psoriasis in a 22-month- } \\
\text { old child successfully treated with etanercept". }\end{array}$ & 3 \\
\hline Safa et $\mathrm{al}^{18}$ & I & $\begin{array}{l}\text { Etanercept } \\
(0.4 \mathrm{mg} / \mathrm{kg} \text { twice weekly) for } 6 \text { months }\end{array}$ & $\begin{array}{l}\text { "Etanercept therapy may be an effective treatment } \\
\text { option for severe psoriasis in children". }\end{array}$ & 3 \\
\hline $\begin{array}{l}\text { Ruiz-Villaverde } \\
\text { et al }{ }^{19}\end{array}$ & 3 & $\begin{array}{l}\text { Etanercept } \\
(25 \mathrm{mg} \text { a week) for } 24 \text { weeks }\end{array}$ & $\begin{array}{l}\text { Efficacy of etanercept in the treatment of three } \\
\text { adolescents with moderate psoriasis. }\end{array}$ & 3 \\
\hline $\begin{array}{l}\text { Papoutsaki } \\
\text { et } \text { al }^{17}\end{array}$ & 4 & $\begin{array}{l}\text { Etanercept } \\
(0.4 \mathrm{mg} / \mathrm{kg} \text { twice weekly })\end{array}$ & $\begin{array}{l}\text { "Etanercept may be efficacious and well tolerated } \\
\text { for severe forms of childhood psoriasis". }\end{array}$ & 3 \\
\hline Hawrot et $\mathrm{al}^{21}$ & 9 & $\begin{array}{l}\text { Etanercept } \\
\text { ( } 25 \mathrm{mg} \text { or } 0.4 \mathrm{mg} / \mathrm{kg} / \text { biweekly } \\
\text { or } 50 \mathrm{mg} \text { once a week) }\end{array}$ & $\begin{array}{l}\text { Results ranged from equivocal/insignificant effect } \\
\text { in two patients to marked and sustained in the } \\
\text { remaining seven patients. }\end{array}$ & 3 \\
\hline Paller et $\mathrm{al}^{22}$ & 211 & $\begin{array}{l}\text { Etanercept } \\
\text { ( } 0.8 \mathrm{mg} / \mathrm{kg} / \text { week for } 12 \text { weeks) } \\
\text { vs placebo followed by } 24 \text { weeks } \\
\text { of Etanercept at the same dose } \\
\text { (open-label). At week } 36,138 \text { patients } \\
\text { were randomized to placebo or } \\
\text { etanercept for } 12 \text { weeks }\end{array}$ & $\begin{array}{l}\text { Etanercept significantly reduced disease severity in } \\
\text { children and adolescents with moderate-to-severe } \\
\text { plaque psoriasis. Four serious adverse events occurred } \\
\text { in the open label part of the study: an ovarian cyst } \\
\text { removal, gastroenteritis, and gastroenteritis-related } \\
\text { dehydration, pneumonia. Longer term data is needed } \\
\text { to fully assess the safety profile of Etanercept. }\end{array}$ & $\mathrm{I}+$ \\
\hline
\end{tabular}

biweekly with $25 \mathrm{mg}$, or $0.4 \mathrm{mg} / \mathrm{kg} /$ dose, or $50 \mathrm{mg}$ once per week; seven patients had a marked and sustained improvement of psoriasis after 3 to 6 months of treatment. ${ }^{21}$

The only reliable and accurate study regarding etanercept treatment for pediatric populations is that of Paller. ${ }^{22}$ In this study, etanercept was administered to children and adolescents (aged 4-17 years) affected by severe plaque psoriasis at a dose of $0.8 \mathrm{mg} / \mathrm{kg}$ once weekly (up to a maximum of $50 \mathrm{mg}$ ). $57 \%$ of patients receiving etanercept achieved PASI 75 compared to $11 \%$ of those receiving placebo $(P<0.001)$ after 12 weeks of treatment. The percentages of patients who achieved PASI $50(75 \%$ vs $23 \%, P<0.001)$ and PASI $90(27 \%$ vs $7 \%$, $P<0.001$ ) were also significantly greater in the etanercept group than in the placebo group at week 12. Efficacy during the open-label phase was sustained through Week 36 .

A sub-analysis of the previous study, assessing the efficacy and safety of etanercept only in children aged 8-17 years showed similar results. ${ }^{23}$

PASI 50, 75, and 90 were maintained throughout week 96 of the extension of the original study, with scores at week 96 of $89 \%, 61 \%$, and $30 \%$, respectively. ${ }^{24}$

Health-related quality of life was evaluated throughout the Children's Dermatology Life Quality Index (CDLQI) and Pediatric Quality of Life Inventory. Patients treated with etanercept demonstrated significantly higher mean percentage improvement in total CDLQI scores from baseline to week 12 compared with those treated with placebo $(52.3 \%$ etanercept vs $17.5 \%$ placebo, $P=0.0001)$. Moreover, at week 12 , patients who achieved $75 \%$ improvement in their
PASI score had higher percentage improvements from baseline in total CDLQI scores than those who did not have $75 \%$ improvement in PASI score. ${ }^{25}$

\section{Safety}

The most commonly reported adverse event was upper respiratory tract infections, occurring in $24.9 \%$ patients treated with etanercept, followed by nasopharyngitis in $17.1 \%$, streptococcal pharyngitis in $12.7 \%$, headache in $11.6 \%$, and sinusitis in $10.5 \%$. Mild to moderate and generally transient injection site reactions were reported in $5.5 \%$ of patients. ${ }^{16,22}$

$1.7 \%$ of patients treated with etanercept developed a total of five serious adverse events: anxiety, serious episodes of gastroenteritis and gastroenteritis-associated dehydration, benign ovarian mass, pneumonia, and postoperative intestinal obstruction. None of these serious adverse events were considered to be related to the study drug and all events resolved without sequel. ${ }^{16,22}$

No opportunistic infections, malignancies, deaths, tuberculosis, or demyelination events were reported through 96 weeks of the study extension. ${ }^{16}$

\section{Conclusion}

Psoriasis is a lifelong disease that often begins during childhood. Despite the fact that psoriasis in children is a common dermatologic condition, properly designed studies regarding its treatment are lacking. Commonly used medications lack scientific evidence showing their efficacy, 
and newer treatments do not have long-term, post-market surveillance data of their safety.

Recent advances in therapeutics for psoriasis have been applied to the pediatric psoriasis population with good results in disease reduction and consequent improvements in quality of life.

To date, etanercept is the only biologic agent approved for plaque psoriasis treatment in children. The treatment is generally well tolerated; mild injection site reactions are the most common adverse events reported in the literature. The theoretical increased risk of tuberculosis and other severe infections occurring during etanercept treatment, although present, is very low both in clinical studies and in post-market use. Regarding the potential onset of malignancy, this has not been seen clinically, but the duration of the follow-up is still not sufficient to determine long-term risk.

The results from the long-term trial to date demonstrate that extended treatment with etanercept at $0.8 \mathrm{mg} / \mathrm{kg}$ once weekly (up to a maximum intended dose of $50 \mathrm{mg}$ ) was generally well tolerated in this group of pediatric patients with moderate to severe plaque psoriasis in the time period studied. ${ }^{16}$

Published data of etanercept use in children show promising results; but further clinical studies are mandatory to confirm its long-term efficacy and safety.

\section{Disclosure}

The authors report no conflicts of interest in this work. The authors state no funding sources for this work.

\section{References}

1. Griffiths CE, Barker JN. Pathogenesis and clinical features of psoriasis. Lancet. 2007;370(9583):263-271.

2. Smith CH, Barker JN. Psoriasis and its management. BMJ. 2006; 333(7564): 380-384.

3. Benoit S, Hamm H. Childhood psoriasis. Clin Dermatol. 2007;25(6): 555-562.

4. Raychaudhuri SP, Gross J. A comparative study of pediatric onset psoriasis with adult onset psoriasis. Pediatr Dermatol. 2000;17(3):174-178.

5. Elder JT, Nair RP, Henseler T, et al. The genetics of psoriasis 2001: the odyssey continues. Arch Dermatol. 2001;137(11):1447-1454.

6. Morris A, Rogers M, Fischer G, Williams K. Childhood psoriasis: a clinical review of 1262 cases. Pediatr Dermatol. 2001;18(3):188-198.

7. Brecher AR, Orlow SJ. Oral retinoid therapy for dermatologic conditions in children and adolescents. J Am Acad Dermatol. 2003;49(2):171-182.
8. Lebwohl M, Ellis C, Gottlieb A, et al. Cyclosporine consensus conference: with emphasis on the treatment of psoriasis. $J$ Am Acad Dermatol. 1998;39(3):464-475.

9. Stern RS, Nichols KT. Therapy with orally administered methoxsalen and ultraviolet A radiation during childhood increases the risk of basal cell carcinoma. The PUVA Follow-up Study. J Pediatr 1996;129(6): 915-917.

10. Lovell DJ, Reiff A, Ilowite NT, et al. Pediatric Rheumatology Collaborative Study Group. Safety and efficacy of up to eight years of continuous etanercept therapy in patients with juvenile rheumatoid arthritis. Arthritis Rheum. 2008;58(5):1496-1504.

11. Morbach H, Richl P, Stojanov S, Lohse P, Girschick HJ. Tumor necrosis factor receptor 1-associated periodic syndrome without fever: cytokine profile before and during etanercept treatment. Rheumatol Int . 2009;30(2):207-212.

12. Colombel JF, Sandborn WJ, Rutgeerts P, et al. Comparison of two adalimumab treatment schedule strategies for moderate-to-severe Crohn's disease: results from the CHARM trial. Am J Gastroenterol. 2009;104(5):1170-1179.

13. Enbrel (etanercept) [full prescribing information]. Thousand Oaks, CA: Immunex Corp, marketed by Amgen and Wyeth Pharmaceuticals; 2009.

14. Shenoi S, Wallace CA. Tumor necrosis factor inhibitors in the management of juvenile idiopathic arthritis: an evidence-based review. Paediatr Drugs. 2010;12(6):367-377.

15. Fabrizi G, Guerriero C, Pagliarello C. Etanercept in infants: suberythrodermic, recalcitrant psoriasis in a 22 month-old child successfully treated with etanercept. Eur J Dermatol. 2007; 17(3):245.

16. Paller AS, Siegfried EC, Eichenfield LF, et al. Long-term etanercept in pediatric patients with plaque psoriasis. $J$ Am Acad Dermatol. 2010;63(5):762-768.

17. Papoutsaki M, Costanzo A, Mazzotta A, Gramiccia T, Soda R, Chimenti S. Etanercept for the treatment of severe childhood psoriasis. Br J Dermatol. 2006;154(1):181-183.

18. Safa G, Loppin M, Bousser AM, Barbarot S. Etanercept in a 7-yearold boy with severe and recalcitrant psoriasis. J Am Acad Dermatol. 2007;56(Suppl 2):S19-S20.

19. Ruiz-Villaverde R, Sánchez-Cano D, Abalos-Medina G. Adolescent plaque psoriasis: our experience using etanercept. J Eur Acad Dermatol Venereol. 2009;23(8):976-977.

20. Floristan U, Feltes R, Ramírez P, Alonso ML, De Lucas R. Recalcitrant palmoplantar pustular psoriasis treated with etanercept. Pediatr Dermatol. 2011;28(3):349-350.

21. Hawrot AC, Metry DW, Theos AJ, Levy ML. Etanercept for psoriasis in the pediatric population: experience in nine patients. Pediatr Dermatol. 2006;23(1):67-71.

22. Paller AS, Siegfried EC, Langley RG, et al. Etanercept treatment for children and adolescents with plaque psoriasis. $N$ Engl J Med. 2008;358(3):241-251.

23. Landells I, Paller AS, Pariser D, et al. Efficacy and safety of etanercept in children and adolescents aged $>$ or $=8$ years with severe plaque psoriasis. Eur J Dermatol. 2010;20(3):323-328.

24. Langley RG, Paller AS, Hebert AA, et al. Patient-reported outcomes in pediatric patients with psoriasis undergoing etanercept treatment: 12-week results from a phase III randomized controlled trial. $J \mathrm{Am}$ Acad Dermatol. 2011;64(1):64-70.
Psoriasis: Targets and Therapy

\section{Publish your work in this journal}

Psoriasis: Targets and Therapy is international, peer-reviewed, open access journal focusing on psoriasis, nail psoriasis, psoriatic arthritis and related conditions, identification of therapeutic targets and the optimal use of integrated treatment interventions to achieve improved outcomes

\section{Dovepress}

and quality of life. Visit http://www.dovepress.com/testimonials.php to read real quotes from published authors. 